\title{
MODEL STRATEGI PEMASARAN JASA KONSULTANSI KONTRAKTOR DI KALIMANTAN SELATAN
}

\author{
Candra Yuliana $^{1}$, Retna Hapsari Kartadipura ${ }^{1}$ \\ ${ }^{1}$ Dosen / Program Studi Teknik Sipil / Fakultas Teknik / Universitas Lambung Mangkurat \\ Korespondensi: candrayuliana@unlam.ac.id
}

\begin{abstract}
Most of the general public of service users have not understood the value of construction consultancy services. This inhibits market opportunities in the private sector for construction consulting services particularly in South Kalimantan. The objective of the research is to create an appropriate marketing strategy for corporation construction consultancy services in South Kalimantan.Strategies can be identified by SWOT analysis, AHP analysis and Importance Performance Analysis. This research is done by giving questionnaire to the service users and construction consulting firms in South Kalimantan. The result of the research are, a model of the marketing strategy of the construction consulting service, Strength-Opportunity strategy, grow and build strategy, service pricing strategy, and a basic strategy. This is a collaboration between the marketing-mix and service quality.
\end{abstract}

Key words: AHP, construction consulting service, marketing strategy, SWOT

\section{PENDAHULUAN}

Pasar jasa konsultansi konstruksi di Provinsi Kalimantan Selatan menunjukkan pertumbuhan yang signifikan pada beberapa tahun terakhir, seiring dengan ragam investasi baik oleh pemerintah maupun swasta. Mayoritas ragam proyek yang ditangani oleh jasa konsultansi konstruksi Provinsi Kalimantan Selatan adalah milik pemerintah baik pemerintah pusat maupun pemerintah daerah. Sementara itu, sebagian kecil berupa proyek milik swasta baik asing maupun nasional.

Meskipun ada peningkatan secara jumlah korporasi jasa konsultansi konstruksi, namun dalam proyek-proyek milik swasta, khalayak umum kurang mengapresiasi dan melibatkan eksistensi korporasi jasa konsultansi konstruksi. Pada umumnya proyekproyek milik swasta ditangani langsung oleh khalayak umum tanpa melibatkan eksistensi korporasi jasa konsultansi konstruksi. Sebagai contoh, dalam merencanakan desain ruko, rumah tinggal, perkantoran swasta ataupun bangunan-bangunan penting lainnya, sangat jarang masyarakat umum menggunakan jasa konsultansi konstruksi untuk dilibatkan dalam tahap perencanaan maupun pengawasannya.
Realitas menunjukkan bahwa ada kesenjangan pemahaman antara user (khalayak umum) dan korporasi jasa konsultansi konstruksi. Pemahaman mengenai nilai yang dapat ditambahkan di dalam produk yang ditawarkan oleh layanan jasa konsultansi konstruksi sangat kurang dipahami oleh masyarakat umum. Hal tersebut menciptakan keterbatasan peluang pasar jasa konsultansi pada proyek-proyek swasta di wilayah Provinsi Kalimantan Selatan. Sebagai perusahaan yang orientasi pelayanannya kepada pengguna jasa/klien, maka jasa konsultansi konstruksi memerlukan strategi pemasaran yang tepat agar dapat diterima oleh segmen pasar yang lebih luas, tidak terbatas hanya pada kalangan tertentu saja yang memahami manfaat dan peran jasa konsultansi di sektor konstruksi.

Tujuan dari penelitian ini adalah untuk memformulasikan model strategi pemasaran yang tepat, agar jasa konsultansi konstruksi di Kalimantan Selatan dapat diterima oleh pengguna jasa dari masyarakat umum, dengan cara mengetahui tingkat pemahaman masyarakat umum pengguna jasa terhadap layanan jasa konsultansi konstruksi, faktorfaktor penyebab terjadinya kesenjangan pemahaman, dan kelayakan biaya jasa 
konsultansi konstruksi agar diterima oleh masyarakat umum pengguna jasa.

\section{KAJIAN TEORI}

Pengertian jasa menurut Zeithaml dan Bitner (2000) merupakan seluruh aktivitas ekonomi yang hasilnya adalah tidak merupakan produk dalam bentuk fisik atau konstruksi, yang secara umum dikonsumsi pada saat yang sama dengan waktu yang dihasilkan dan memberikan nilai tambah, seperti kenyamanan, hiburan, kesenangan, atau kesehatan [1]. Sedangkan menurut Lovelock (2004) menyatakan bahwa jasa mempunyai tiga karakteristik utama yaitu more intangible than tangible (cenderung tidak berwujud), simultaneous production and consumption (produksi dan konsumsi serentak), less standardized and uniform (kurang terstandarisasi dan seragam) [2].

Dalam strategi pemasaran jasa, Kotler dan Keller (2007) menjelaskan bahwa ada empat komponen yang tercakup dalam kegiatan bauran pemasaran (marketing mix) sebagai berikut: product, price, promotion, place and distribution [3]. Dalam hal ini, Booms dan Bitner (2001) mengusulkan 3P sebagai tambahan untuk pemasaran jasa yaitu people, process, Physical evidence [3].

Persepsi konsumen terhadap kualitas pelayanan merupakan penilaian menyeluruh atas keunggulan suatu pelayanan. Diakui banyak ragam pendapat tentang dimensi kualitas pelayanan (service quality). Namun, pada penelitian ini, peneliti merujuk dimensi kualitas pelayanan (service quality) yang diunggah oleh Parasuraman, dkk (1988) [4]. Alasannya adalah mereka telah berhasil membuat skala pengukuran kualitas pelayanan (service quality) yang bersifat multi dimensi sebagai berikut: reliability, responssiveness, assurance, empathy, tangibles [4].

$$
\text { Kotler dan Armstrong }
$$

menjelaskan bahwa ada tiga jenis pemasaran dalam korporasi jasa, yaitu external marketing, internal marketing, interactive marketing [5]. Menurut Hasan (2013) dalam perencanaan strategi pemasaran harus mengacu pada lima elemen kunci yang saling berkaitan yaitu pemilihan pasar, perencanaan produk, penetapan harga, sistem distribusi, dan komunikasi pemasaran [6].

David (2006) menjelaskan bahwa proses manajemen srategis terdiri dari tiga tahap yaitu fomulasi atau perumusan strategi, implementasi atau pelaksanaan strategi, dan evaluasi strategi. Formulasi atau perumusan strategi mencakup kegiatan mengembangkan visi dan misi organisasi, mengidentifikasi peluang dan ancaman eksternal organisasi, menetapkan tujuan-tujuan jangka panjang organisasi, membuat sejumlah strategi alternatif untuk organisasi dan memilih strategi tertentu untuk digunakan [7]

David (2006) menjelaskan bahwa IFAS (Internal Strategic Factor Analysis Summary) dan EFAS (External Strategic Factor Analysis Summary) merupakan suatu alat ukur yang efektif untuk menyajikan micro and macro environment analysis ke dalam matrix yang telah diberi bobot dan rating tertentu untuk mengetahui seberapa besar strength and weakness yang ada di micro environment atau lingkungan internal.

Metode AHP merupakan sebuah metode untuk mengambil keputusan dengan efektif atas persoalan yang kompleks dengan menyederhanakan dan mempercepat proses pengambilan keputusan dengan memecahkan persoalan tersebut kedalam bagian-bagiannya, menata bagian atau variabel ini dalam suatu susunan hirarki, memberi nilai numerik pada pertimbangan subyektif tentang pentingnya tiap variabel dan mensintesis berbagai pertimbangan ini untuk menetapkan variabel yang mana yang memiliki prioritas paling tinggi dan bertindak untuk mempengaruhi hasil pada situasi tersebut (Saaty, 2008) [8].

Importance Performance Analysis merupakan perhitungan mengenai tingkat kesesuaian antara tingkat kepentingan dengan tingkat pelaksanaan. Importance Performance Analysis merupakan hasil perbandingan antara service quality performance yang merupakan kinerja korporasi dan skor rata- rata expectation yang merupakan kepentingan pengguna jasa (user). Importance Performance Analysis inilah yang akan menentukan urutan prioritas penanganan indikator-indikator untuk peningkatan kualitas pelayanan (service quality) yang diharapkan (Supranto, 2006) [9].

Menurut Kotler (2000) dan Zeithaml, dkk (2000) hasil yang diperoleh dari tingkat kesesuaian dapat dilihat dalam diagram kartesius. Fungsi diagram kartesius adalah untuk mengukur tingkat kesenjangan atau gap antara performance dengan expectation pengguna jasa (user) serta untuk memberikan 
informasi kepada korporasi penyedia jasa tentang atribut-atribut yang perlu diperbaiki dan ditingkatkan kinerjanya sehingga dapat menimbulkan kepuasan konsumen (customer satisfaction) [10] [11].

\section{METODE PENELITIAN}

Data primer diperoleh berdasarkan penyebaran kuesioner yang berkonten sejumlah item pernyataan berikut alternatif pernyataan kepada para responden. Populasi sasaran dalam penelitian ini adalah korporasi jasa konsultansi konstruksi yang terdaftar di DPD INKINDO sebanyak 135 korporasi. Responden dalam penelitian ini ada dua kategori yaitu responden dari pihak pengguna jasa dan responden dari pihak korporasi jasa konsultansi (asosiasi INKINDO). Responden dari masing-masing pihak diambil sebanyak 101 responden. Pakar yang dijadikan rujukan untuk kuesioner ini diambil sebanyak 20 orang dari pihak akademik (dosen) dan dan porfesi konsultan. Kuesioner meliputi data pernyataan responden terhadap kinerja dan harapan layanan jasa konsultansi konstruksi; pernyataan responden terhadap faktor internal dan eksternal korporasi; dan penilaian responden terhadap penetapan kelayakan harga jasa konsultansi konstruksi. Data sekunder berupa data eksternal seperti buku, jurnal, majalah dan terbitan lainnya, maupun publikasi melalui internet yang terkait dengan penelitian.

Variabel-variabel yang diteliti untuk analisis SWOT meliputi variabel strength, variabel weakness, variabel opportunity, dan variabel threats. Setiap variabel tersebut memiliki dimensi, indikator dan skala pengukurannya Ansoff (2007) [12]. Rangkuti (2011) menjelaskan bahwa indikator-indikator dalam dimensi di setiap variabel diistilahkan dengan key success factor [13]. Dimensi setiap variabel pada penelitian ini dapat dilihat pada Tabel 1. Pemilihan kriteria tersebut berdasarkan keunggulan dan kekurangan yang dimiliki oleh sebuah korporasi, kesempatan baru untuk menambah keuntungan korporasi, dan berdasarkan situasi penting yang tidak menguntungkan bagi korporasi.

Dengan menggunakan analisis SWOT dan IE Matrix dapat diidentifikasi posisi dan kemampuan korporasi untuk merebut pasar sektor swasta melalui pemanfaatan kekuatan dan peluang yang ada secara maksimal serta meminimumkan kelemahan dan ancaman yang bakal muncul. Rangkuti (2011) menjelaskan bahwa TOWS matrix merupakan bentuk penjabaran dari analisis SWOT dalam bentuk matriks. Hal ini dilakukan untuk mendapatkan gambaran yang jelas posisi strategi alternatif apa yang harus dilaksanakan korporasi dalam masalah pemasaran jasa konsultansi konstruksi [14].

Penilaian khalayak umum terhadap produk yang ditawarkan oleh jasa konsultansi konstruksi sebatas produk. Bukan pada proses hasil kerja professional yang melibatkan berbagai macam tenaga ahli di dalamnya. Fenomena ini sebagai salah satu faktor penyebab pihak jasa konsultansi sulit untuk menetapkan kelayakan biaya jasa konsultansi konstruksi pada user. Penentuan standar biaya jasa konsultansi yang telah ditetapkan pemerintah juga sulit untuk diterapkan pada proyek-proyek swasta yang mayoritas user nya adalah khalayak umum. Realitas juga menunjukkan bahwa terjadi fenomena adanya tawaran jasa desain yang diberikan oleh kontraktor secara gratis kepada user untuk meningkatkan daya saing kontraktor di sektor swasta. Maka diperlukan suatu strategi kelayakan harga jasa konsultansi konstruksi dengan menggunakan analisis Analytical Hierarchy Process. Sedangkan untuk mengetahui kesenjangan persepsi antara pihak pengguna jasa dengan jasa konsultansi konstruksi dilakukan dengan menggunakan analisis Importance Performance Analysis.

Tabel 1. Variabel penelitian

\begin{tabular}{|l|l|}
\hline Variabel & Dimensi \\
\hline Strength & Bauran Pemasaran Jasa \\
\cline { 2 - 2 } & Kualitas Layanan Jasa \\
\cline { 2 - 2 } & Corporate Culture \\
\hline \multirow{5}{*}{ Opeakness } & Bauran Pemasaran Jasa \\
\cline { 2 - 2 } & Kualitas Layanan Jasa \\
\cline { 2 - 2 } & Organization Climate \\
\hline \multirow{5}{*}{ Threat } & Stabilitas Politik dan Keamanan \\
\cline { 2 - 2 } & Stabilitas ekonomi \\
\cline { 2 - 2 } & Pengembangan geografi \\
\cline { 2 - 2 } & Pengembangan demografi \\
\cline { 2 - 2 } & Regulasi dan hokum \\
\cline { 2 - 2 } & Pendatang baru \\
\cline { 2 - 2 } & $\begin{array}{l}\text { Kekuatan tawar menawar Pengguna } \\
\text { jasa konsultansi Konstruksi }\end{array}$ \\
\cline { 2 - 2 } & $\begin{array}{l}\text { Kompetisi antar penyedia jasa } \\
\text { konsultansi konstruksi }\end{array}$ \\
\hline
\end{tabular}




\section{HASIL DAN PEMBAHASAN}

\subsection{Analisis SWOT}

Berdasarkan perhitungan distribusi frekuensi data reponden, untuk variabel IFAS didapat nilai mean terendah sebesar 2,17 terletak pada dimensi weakness. Nilai tersebut menunjukkan bahwa rata-rata responden menyatakan "lemah" (L) dalam interval dari 2,1 sampai 3,0. Sementara itu, nilai mean tertinggi sebesar 2,50 pada dimensi strength. Nilai tersebut menunjukkan bahwa rata-rata responden menyatakan "kuat" (K) dalam interval dari 2,1 sampai 3,0. Pada variabel EFAS didapat nilai mean terendah sebesar 2,45 terletak dalam dimensi threat. Nilai tersebut menunjukkan bahwa rata-rata responden menyatakan "mengancam" (M) dalam interval dari 2,1 sampai 3,0. Sementara itu, nilai mean tertinggi sebesar 2,61 dalam dimensi opportunity. Nilai tersebut menunjukkan bahwa rata-rata responden menyatakan "berpeluang" (B) dalam interval dari 2,1sampai 3,0, seperti pada Tabel 2.

Tabel 2. Analisis statistik deskriptif

\begin{tabular}{c|c|c|c}
\hline Variabel & Dimensi & Mean & Deviasi standar \\
\hline \multirow{2}{*}{ IFAS } & Strength & 2,51 & 0,50 \\
& Weakness & 2,17 & 0,58 \\
\cline { 2 - 4 } EFAS & Opportunity & 2,61 & 0,52 \\
& Threat & 2,45 & 0,63 \\
\hline
\end{tabular}

Variabel IFAS dan EFAS membentuk koordinat yaitu 2,88 (IFAS);3,00 (EFAS). Koordinat ini memposisikan formulasi strategi bisnis pada kuadran II tergolong growth and build (Gambar 1)

Bila pada IFAS-EFAS matrix atau GE matrix, total IFAS weighted score dan total EFAS weighted score sebagai faktor determinan bagi tersusunnya koordinat dan memposisikan kuadran. Sedangkan pada SWOT matrix, besaran weighted score setiap dimensi pada IFAS dan EFAS sebagai faktor determinan bagi tersusunnya empat pasangan yaitu pasangan $\mathrm{S}-\mathrm{O}$, pasangan $\mathrm{S}-\mathrm{T}$, pasangan W-O, dan pasangan W-T. Pada Tabel 3 terlihat bahwa besaran nilai pasangan yang tertinggi sebesar 3,16 terletak pada pasangan S-O Pasangan S-O merupakan strategi yang memanfaatkan seluruh kekuatan untuk merebut dan memanfaatkan peluang sebesar-besarnya korporasi jasa konsultansi konstruksi di
Kalimantan Selatan. Adapun formulasi strategi bisnis detailnya dapat dilihat pada Tabel 4.

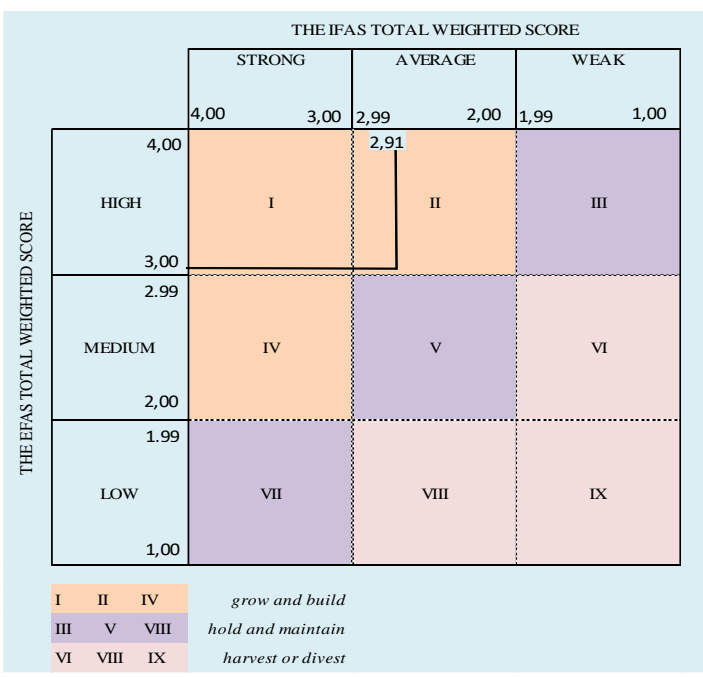

Gambar 1. IFAS-EFAS Matrix atau GE Matrix

Tabel 3. SWOT matrix

\begin{tabular}{c|c|c|c}
\hline \multicolumn{2}{c|}{} & \multicolumn{2}{c}{ Kolom } \\
\cline { 3 - 4 } \multicolumn{2}{c|}{} & Strenght & Weakness \\
\hline & \multirow{3}{*}{ Opportunity } & $(1,61+1,55)$ & $(1,27+1,55)$ \\
& & 3,16 & $\mathrm{~W}-\mathrm{O}$ \\
& \multirow{3}{*}{ Threat } & $(1,61+1,45)$ & $(1,27+1,45)$ \\
& & 3,06 & $\mathrm{WT}$ \\
& & \multicolumn{2}{c}{2,72} \\
\hline
\end{tabular}

TOWS matrix merupakan tindak lanjut dari SWOT matrix. Bila pada SWOT matrix menekankan detail strategi bisnis per key success factor sedangkan TOWS matrix lebih menekankan pada rangkuman formulasi strategi bisnis (Gambar 2).

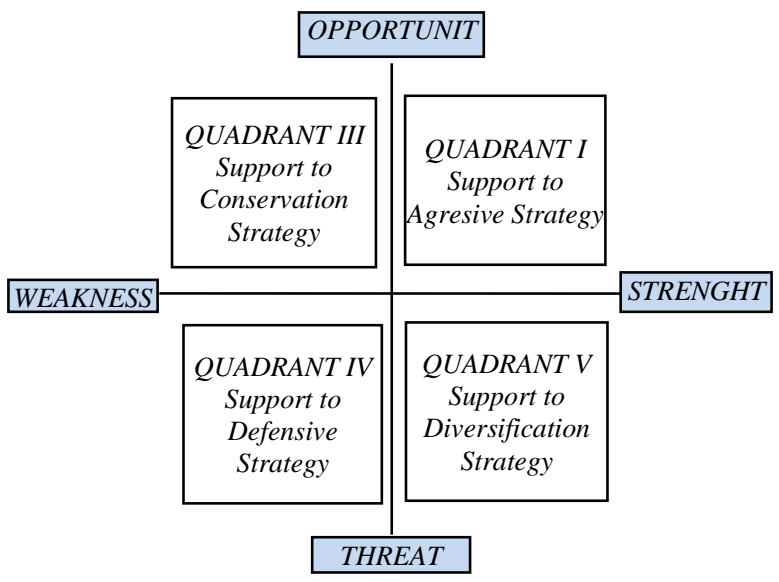

Gambar 2. TOWS matrix 
Tabel 4. Formulasi strategi S-O

\begin{tabular}{|c|c|c|}
\hline IFAS & \multicolumn{2}{|r|}{ Strenght } \\
\hline \multirow{21}{*}{ 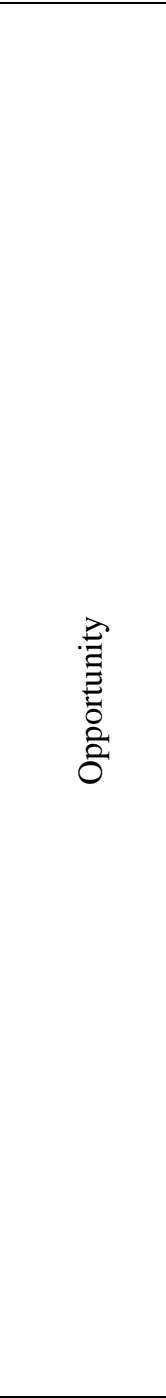 } & $\mathrm{S}_{1}$ & Produk jasa konsultansi konstruksi yang dimiliki korporasi \\
\hline & $\mathrm{O}_{1}$ & Kehidupan demokrasi yang semakin dewasa di Kalimantan Selatan \\
\hline & Solusi & Meningkatkan reliability khususnya kehandalan SDM dan peralatan yang memadai \\
\hline & $\mathrm{S}_{2}$ & Kantor pusat dan pendistribusian jasa konsultansi konstruksi yang dimiliki \\
\hline & $\mathrm{O}_{2}$ & Keamanan dan ketertiban dalam masyarakat di Provinsi Kalimantan Selatan \\
\hline & Solusi & $\begin{array}{l}\text { Meningkatkan kemudahan akses baik yang bersifat lokasi maupun homepage } \\
\text { (website) dalam rangka memudahkan pelanggan (user) mendapatkan informasi }\end{array}$ \\
\hline & $\mathrm{S}_{3}$ & Sumber daya manusia yang dimiliki jasa konsultansi konstruksi yang dimiliki \\
\hline & $\mathrm{O}_{3}$ & Pertumbuhan PDB regional di provinsi Kalimantan Selatan \\
\hline & Solusi & $\begin{array}{l}\text { Meningkatkan empathy khususnya terkait dengan memahami kebutuhan pelanggan } \\
\text { (user) jasa konsultansi konstruksi }\end{array}$ \\
\hline & $\mathrm{S}_{4}$ & Dokumen referensi pengalaman kerja beberapa proyek yang dimiliki korporasi \\
\hline & $\mathrm{O}_{4}$ & $\begin{array}{l}\text { Pertumbuhan pasar jasa konsultansi konstruksi di lingkup wilayah Kalimantan } \\
\text { Selatan }\end{array}$ \\
\hline & Solusi & $\begin{array}{l}\text { Meningkatkan responsiveness khususnya terkait daya tanggap pada klaim. Selain itu } \\
\text { perlu dipertimbangkan pula fleksibilitas sistem pembayaran. }\end{array}$ \\
\hline & $\mathrm{S}_{5}$ & Tingkat kehandalan tenaga teknis professional yang dimiliki korporasi \\
\hline & $\mathrm{O}_{5}$ & $\begin{array}{l}\text { Tingkat kesejahteraan masyarakat semakin membaik mendorong perlu mendapat } \\
\text { perhatian khusus dari pemerintah daerah pada masalah pembangunan dan } \\
\text { pemberdayaan masyarakat }\end{array}$ \\
\hline & Solusi & $\begin{array}{l}\text { Mengoptimalkan peralatan yang memadai, memahami kebutuhan user dan ketepatan } \\
\text { waktu serta kualitas hasil kerja }\end{array}$ \\
\hline & $\mathrm{S}_{6}$ & $\begin{array}{l}\text { Prasarana dan sarana yang dimiliki korporasi dalam menangani proyek jasa } \\
\text { konsultansi konstruksi }\end{array}$ \\
\hline & $\mathrm{O}_{6}$ & Pemekaran wilayah baru di lingkup provinsi Kalimantan Selatan \\
\hline & Solusi & $\begin{array}{l}\text { Meningkatkan peralatan yang memadai dan memudahkan akses baik lokasi maupun } \\
\text { homepage (website) sehingga masyarakat pengguna jasa konsultansi konstruksi yang } \\
\text { tersebar di beberapa wilayah di lingkup propinsi Kalimantan Selatan mudah } \\
\text { mendapatkan informasi. }\end{array}$ \\
\hline & $\mathrm{S}_{7}$ & Visi, Misi dan keberadaan Standard Operation Procedure (SOP) yang dimiliki \\
\hline & $\mathrm{O}_{7}$ & Pertumbuhan penduduk \\
\hline & Solusi & $\begin{array}{l}\text { Meningkatkan Assurance khususnya ketepatan waktu dan kualitas hasil kerja. Untuk } \\
\text { maksud tersebut, perlu dilakukan tindakan peningkatan SDM, dan peralatan yang } \\
\text { memadai }\end{array}$ \\
\hline
\end{tabular}

Konfigurasi formulasi strategi bisnis jasa konsultansi konstruksi adalah S-O. Pasangan S$\mathrm{O}$ ini menjadikan formulasi strategi bisnis jasa konsultansi konstruksi pada kuadran I di TOWS matrix yaitu support to agresive strategy.

\subsection{Analisis AHP}

Dengan mencermati perolehan bobot yang dilihat dari nilai eigen value pada setiap dimensi seperti yang terlihat pada sumber tabulasi data yang diolah dengan aplikasi Microsoft Office-Excel 2013, SPSS v 24 for windows release, dan Expert Choice v 15, maka eigen value terendah sebesar 0,05 terletak pada dimensi empathy. Sementara itu, eigen value tertinggi sebesar 0,47 terletak pada dimensi reliability. Dalam hal ini sub kriteria tertinggi sebesar 0,64 terletak pada sub kriteria "SDM yang handal." Kemudian disusul sub kriteria "Peralatan yang memadai" sebesar 0,25 dan sub kriteria "Kemudahan pembayaran" sebesar 0,10. Hal ini dituangkan pada Tabel 5.

Sedangkan untuk mendapatkan kelayakan harga jasa konsultansi, dari hasil perhitungan diperoleh bobot terendah yang dilihat dari nilai eigen value sebesar 0,101 pada price $2,5 \%$ sampai $3,5 \%$ dari nilai fisik. Sementara itu, bobot atau nilai eigen value tertinggi sebesar 0,64 pada price 5,6\% sampai $4,65 \%$ dari nilai fisik. Untuk mendukung formulasi strategi bisnis jasa konsultansi konstruksi di wilayah propinsi Kalimantan Selatan maka kelayakan biaya berada $5,6 \%$ 
sampai 4,65\% dari nilai fisik. Uraian ini dituangkan pada Tabel 6.

Tabel 5. Bobot atau nilai eigen value setiap dimensi perbandingan berpasangan

\begin{tabular}{c|l|l|c}
\hline $\begin{array}{c}\text { Priori } \\
\text { tas }\end{array}$ & \multicolumn{1}{|c|}{ Kriteria } & \multicolumn{1}{|c}{ Sub Kriteria } & $\begin{array}{c}\text { Eigen } \\
\text { Value }\end{array}$ \\
\hline 1 & Reliability & 0,47 \\
\hline & & $\begin{array}{l}\text { SDM yang } \\
\text { handal }\end{array}$ & 0,64 \\
\hline & $\begin{array}{l}\text { Peralatan yang } \\
\text { memadai }\end{array}$ & 0,25 \\
\hline 3 & Tangible & $\begin{array}{l}\text { Kemudahan } \\
\text { pembayaran }\end{array}$ & 0,10 \\
\hline 4 & Assurance & $\begin{array}{l}\text { Jaminan diakses } \\
\text { ketepatan waktu } \\
\text { dan kualitas }\end{array}$ & 0,22 \\
\hline 5 & $\begin{array}{l}\text { Responsive } \\
\text { ness }\end{array}$ & $\begin{array}{l}\text { Daya tanggap } \\
\text { pada klaim }\end{array}$ & 0,09 \\
\hline & Empathy & $\begin{array}{l}\text { Paham } \\
\text { kebutuhan user }\end{array}$ & 0,05 \\
\hline
\end{tabular}

Tabel 6. Bobot atau eigen value price

\begin{tabular}{|c|c|c|}
\hline Prioritas & $\begin{array}{c}\text { Kelayakan Biaya } \\
\text { Jasa Konsultansi Konstruksi }\end{array}$ & $\begin{array}{l}\text { Eigen } \\
\text { Value }\end{array}$ \\
\hline 1 & $\begin{array}{l}\text { Price } 5,6 \%-4,65 \% \text { dari } \\
\text { nilai fisik }\end{array}$ & 0,64 \\
\hline 2 & $\begin{array}{l}\text { Price } 3,5 \%-5 \% \text { dari nilai } \\
\text { fisik }\end{array}$ & 0,25 \\
\hline 3 & $\begin{array}{l}\text { Price } 2,5 \%-3,5 \% \text { dari } \\
\text { nilai fisik }\end{array}$ & 0,10 \\
\hline
\end{tabular}

\subsection{Analisis Importance Performance Analysis}

Untuk mengetahui faktor-faktor yang menyebabkan kesenjangan pemahaman pengguna jasa terhadap layanan jasa konsultansi konstruksi di Kalimantan Selatan, maka dilakukan analisa penilaian kepuasan pengguna jasa pada variabel PSQ (Performance Service Quality) dan variabel ISQ (Importance Service Quality) jasa konsultansi konstruksi.

Berdasarkan sumber tabulasi data jumlah mean pada variabel PSQ yang dibagi dengan jumlah banyaknya responden didapat nilai mean terendah sebesar 2,93 terdapat dalam dimensi tangible. Nilai tersebut menunjukkan bahwa rata-rata responden menyatakan "tidak puas" (TP) dalam interval 2,00 sampai 2,95 .
Sementara itu, nilai mean tertinggi sebesar 3,35 terdapat dalam dimensi reliability. Nilai tersebut menunjukkan bahwa rata- rata responden menyatakan "cukup puas" (CP) dalam interval 3,0 sampai 3,95.

Berdasarkan sumber tabulasi data jumlah mean pada variabel ISQ yang dibagi dengan jumlah banyaknya responden maka didapat nilai mean terendah sebesar 3,61 terdapat dalam dimensi empathy. Nilai tersebut menunjukkan bahwa rata-rata responden menyatakan "cukup penting diperbaiki" (CPD) dalam interval 3,00 sampai 3,95. Sementara itu, nilai mean tertinggi sebesar 3,90 dalam dimensi tangible. Nilai tersebut menunjukkan bahwa rata-rata responden menyatakan "cukup penting diperbaiki" (CPD) dalam interval 3,0 sampai 3,95. Secara keseluruhan analisis statistik deskriptif tersebut di atas, dituangkan pada Tabel 7.

Tabel 7. Statistik deskriptif Importance Performance Analysis

\begin{tabular}{l|l|c|c}
\hline Variabel & \multicolumn{1}{|c|}{ Dimensi } & Mean & $\begin{array}{c}\text { Deviasi } \\
\text { Standar }\end{array}$ \\
\hline \multirow{4}{*}{ PSQ } & Reliability & 3,35 & 0,489 \\
\cline { 2 - 4 } & Responsiveness & 3,27 & 0,63 \\
\cline { 2 - 4 } & Empathy & 3,27 & 0,75 \\
\cline { 2 - 4 } & Assurance & 2,96 & 0,68 \\
\cline { 2 - 4 } & Tangible & 2,93 & 0,87 \\
\hline \multirow{7}{*}{ ISQ } & Reliability & 3,71 & 0,78 \\
\cline { 2 - 4 } & Responsiveness & 3,65 & 0,87 \\
\cline { 2 - 4 } & Empathy & 3,61 & 0,78 \\
\cline { 2 - 4 } & Assurance & 3,78 & 0,77 \\
\cline { 2 - 4 } & Tangible & 3,90 & 0,84 \\
\hline
\end{tabular}

Kualitas pelayanan jasa konsultansi konstruksi dengan hasil secara keseluruhan kesenjangan antara performance dengan importance sebesar -0,57. Dalam hal ini, kesenjangan terendah sebesar $-0,34$ pada dimensi empathy. Sedangkan kesenjangan tertinggi sebesar $-0,97$ pada dimensi tangible seperti terlihat pada Tabel 8. 
Tabel 8. Rekapitulasi kesenjangan antara PSQ dengan ISQ

\begin{tabular}{|c|c|c|c|c|c|}
\hline \multirow[b]{2}{*}{ NO } & \multirow{2}{*}{\multicolumn{2}{|c|}{ DIMENSI }} & \multicolumn{2}{|c|}{ MEAN } & \multirow[b]{2}{*}{$\begin{array}{l}\text { GAP } \\
(\mathrm{P}-\mathrm{I})\end{array}$} \\
\hline & & & $\begin{array}{l}\text { Perfor } \\
\text { mance }\end{array}$ & $\begin{array}{c}\text { Import } \\
\text { ance }\end{array}$ & \\
\hline \multirow{2}{*}{1} & \multirow{2}{*}{ Reliability } & $\mathrm{n}=101$ & \multirow{2}{*}{3,35} & \multirow{2}{*}{3,71} & \multirow{2}{*}{$-0,36$} \\
\hline & & $\mathrm{k}=4$ & & & \\
\hline \multirow[b]{2}{*}{2} & \multirow[b]{2}{*}{$\begin{array}{l}\text { Responsive } \\
\text { ness }\end{array}$} & $\mathrm{n}=10$ & \multirow[b]{2}{*}{3,27} & \multirow[b]{2}{*}{3,65} & \multirow[b]{2}{*}{$-0,38$} \\
\hline & & $\mathrm{k}=3$ & & & \\
\hline \multirow{2}{*}{3} & \multirow{2}{*}{ Empathy } & $\mathrm{n}=101$ & \multirow{2}{*}{3,27} & \multirow{2}{*}{3,61} & \multirow{2}{*}{$-0,34$} \\
\hline & & $\mathrm{k}=3$ & & & \\
\hline \multirow{2}{*}{4} & \multirow{2}{*}{ Assurance } & $\mathrm{n}=101$ & \multirow{2}{*}{2,96} & \multirow{2}{*}{3,78} & \multirow{2}{*}{$-0,82$} \\
\hline & & $\mathrm{k}=2$ & & & \\
\hline \multirow{2}{*}{5} & \multirow{2}{*}{ Tangible } & $\mathrm{n}=101$ & \multirow{2}{*}{2,93} & \multirow{2}{*}{3,90} & \multirow{2}{*}{$-0,97$} \\
\hline & & $\mathrm{k}=2$ & & & \\
\hline \multicolumn{3}{|c|}{ Mean Service Quality (SQ) } & 3,16 & 3,73 & $-0,57$ \\
\hline
\end{tabular}

Adanya kesenjangan dari masing-masing atribut pada setiap dimensi kualitas pelayanan, menimbulkan tingkat kepuasan pelanggan (customer satisfaction level) yang beragam pula. Kemudian ditindaklanjuti dengan analisis tingkat kepuasan pelanggan yang dilakukan secara dimensional.

Dari seluruh hasil perhitungan per dimensional, maka dapat disusun rekapitulasi untuk tingkat kepuasan pelanggan (customer satisfaction level), di mana dari hasil perhitungan diperoleh nilai sebesar 0,85 . Dalam hal ini, tingkat kepuasan pelanggan (customer satisfaction level) terendah sebesar 0,75 pada dimensi tangible. Sedangkan tingkat kepuasan pelanggan (customer satisfaction level) tertinggi sebesar 0,91 pada dimensi empathy seperti terlihat pada Tabel 9.

Tabel 9. Rekapitulasi Customer Satisfaction Level Jasa Konsultansi Konstruksi

\begin{tabular}{|c|c|c|c|c|c|c|}
\hline \multirow{3}{*}{$\begin{array}{c}\text { No } \\
1\end{array}$} & \multirow{3}{*}{\begin{tabular}{|l} 
Dimensi \\
Reliability
\end{tabular}} & \multicolumn{2}{|c|}{ Mean } & \multirow{2}{*}{\multicolumn{3}{|c|}{$\begin{array}{c}\text { Customer } \\
\text { Satisfaction } \\
\text { Level } \\
(\mathrm{P} / \mathrm{I})\end{array}$}} \\
\hline & & \multirow{2}{*}{$\begin{array}{c}\begin{array}{c}\text { Perfor } \\
\text { mance } \\
(P)\end{array} \\
3,35\end{array}$} & \multirow{2}{*}{ 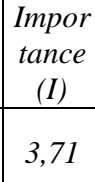 } & & & \\
\hline & & & & 0,90 & 0,75 & 0,99 \\
\hline 2 & Responsiveness & 3,27 & 3,65 & 0,90 & 0,75 & 0,99 \\
\hline 3 & Empathy & 3,27 & 3,61 & 0,91 & 0,75 & 0,99 \\
\hline 4 & Assurance & 2,96 & 3,78 & 0,79 & 0,75 & 0,99 \\
\hline 5 & Tangible & 2,93 & 3,90 & 0,75 & 0,75 & 0,99 \\
\hline & $\begin{array}{c}\text { Mean Customer } \\
\text { Satisfaction } \\
\text { Level }\end{array}$ & 3,16 & 3,73 & 0,85 & 0,75 & 0,99 \\
\hline
\end{tabular}

Pada Tabel 9 dapat ditarik kesimpulan bahwa untuk meningkatkan kepuasan pelanggan (customer satisfaction level) yang lebih optimal diperlukan langkah pembenahan dimensi tangible secara berkesinambungan (sustainable).

Rekapitulasi untuk posisi koordinat dan kuadran setiap dimensi pada service quality jasa konsultansi konstruksi seperti terlihat pada Tabel 10 dan Gambar 3, dimana nilai koordinat masing-masing Performance dan Importance dibandingkan dengan nilai mean Performance Service Quality (PSQ) dan Importance Service Quality (ISQ). Kuadran A harus menjadi prioritas utama dalam kebijakan korporasi jasa konsultansi konstruksi supaya ada peningkatan service quality.

Sedangkan untuk kuadran D kebijakannya dinilai berlebihan oleh pelanggan (user) jasa konsultansi konstruksi.

Tabel 10. Rekapitulasi posisi koordinat dan kuadran pada Service Quality

\begin{tabular}{|c|c|c|c|c|c|c|}
\hline \multirow[b]{2}{*}{ No } & \multirow[b]{2}{*}{ Dimensi } & \multicolumn{2}{|c|}{ Koordinat } & \multirow{2}{*}{\multicolumn{3}{|c|}{ Posisi Kuadran }} \\
\hline & & \multirow{4}{*}{$\begin{array}{c}\begin{array}{c}\text { Perfor } \\
\text { mance } \\
(\mathrm{P})\end{array} \\
3,35\end{array}$} & $\begin{array}{l}\text { Impor } \\
\text { tance } \\
\text { (I) }\end{array}$ & & & \\
\hline \multirow{3}{*}{1} & \multirow{3}{*}{ Reliability } & & \multirow{3}{*}{3,71} & & \multirow{3}{*}{$\mathrm{D}$} & \multirow{3}{*}{ Berlebihan } \\
\hline & & & & $3,35>3,16$ & & \\
\hline & & & & $3,71<3,73$ & & \\
\hline \multirow{2}{*}{2} & \multirow{2}{*}{$\begin{array}{l}\text { Respon } \\
\text { siveness }\end{array}$} & \multirow{2}{*}{3,27} & \multirow{2}{*}{3,65} & $3,27>3,16$ & \multirow{2}{*}{$\mathrm{D}$} & \multirow{2}{*}{ Berlebihan } \\
\hline & & & & $3,65<3,73$ & & \\
\hline \multirow{2}{*}{3} & \multirow{2}{*}{ Empathy } & \multirow{2}{*}{3,27} & \multirow{2}{*}{3,61} & $3,27>3,16$ & \multirow{2}{*}{$\mathrm{D}$} & \multirow{2}{*}{ Berlebihan } \\
\hline & & & & $3,61<3,73$ & & \\
\hline \multirow{2}{*}{4} & \multirow{2}{*}{ ssurance } & \multirow{2}{*}{2,96} & \multirow{2}{*}{3,78} & $2,96<3,16$ & \multirow{2}{*}{ A } & \multirow{2}{*}{$\begin{array}{l}\text { Prioritas } \\
\text { Utama }\end{array}$} \\
\hline & & & & $3,78>3,73$ & & \\
\hline \multirow{2}{*}{5} & \multirow{2}{*}{ Tangible } & \multirow{2}{*}{2,93} & \multirow{2}{*}{3,90} & $2,93<3,16$ & \multirow{2}{*}{ A } & \multirow{2}{*}{$\begin{array}{l}\text { Prioritas } \\
\text { Utama }\end{array}$} \\
\hline & & & & $3,90>3,73$ & & \\
\hline \multicolumn{2}{|c|}{$\begin{array}{l}\text { Mean Service } \\
\text { Quality (SQ) }\end{array}$} & 3,16 & 3,73 & \multicolumn{3}{|c|}{ Penentu Kuadran Dimensional } \\
\hline
\end{tabular}

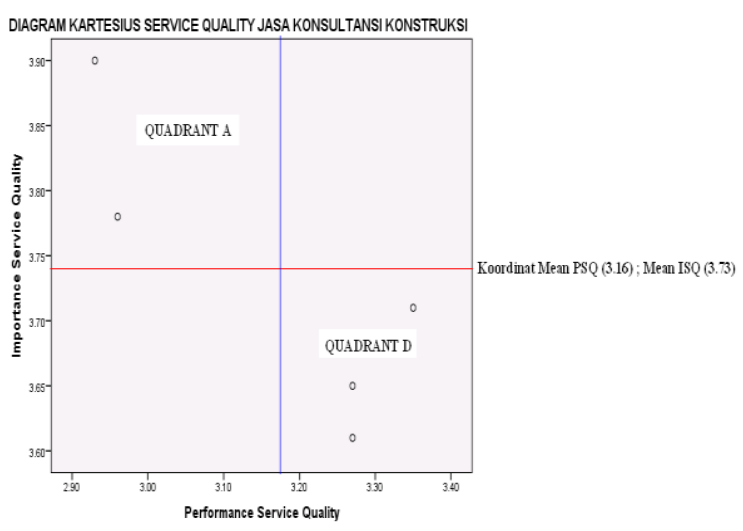

Gambar 3. Diagram Kartesius Setiap Dimensi pada Service Quality 


\section{KESIMPULAN}

Hasil penelitian ini memberikan suatu model formulasi strategi pemasaran jasa konsultansi konstruksi yang dapat diterapkan di Kalimantan Selatan melalui strategi kolaborasi Strength-Opportunity, strategi growth and build, strategi harga jasa, dan basic strategy yaitu kolaborasi antara marketing-mix dan service quality.

Penilaian terhadap variabel performance, tingkat pemahaman responden yang tertinggi terletak pada dimensi reliability layanan jasa konsultansi konstruksi. Sedangkan tingkat pemahaman masyarakat umum yang terendah terletak pada dimensi tangible yaitu pada indicator kejelasan kantor korporasi, kemudahan akses dan kelengkapan sarana yang memadai yang dimiliki korporasi jasa konsultansi, sehingga cukup penting diperbaiki.

Faktor-faktor penyebab terjadinya kesenjangan pemahaman antara pengguna jasa dari masyarakat umum dengan penyedia jasa konsultansi konstruksi diwujudkan dalam besaran kesenjangan antara kinerja (performance) dengan apa yang diharapkan (importance). Secara keseluruhan, dimensi tangible merupakan dimensi yang memiliki nilai kesenjangan tertinggi sehingga perlu diperbaiki agar service quality bisa optimal untuk meminimalisir faktor-faktor penyebab kesenjangan pemahaman tersebut.

\section{DAFTAR PUSTAKA}

[1] Zeithaml, Valarie A and Mary Jo Bitner. 2000. Service Marketing. Singapore. McGraw Hill Companies Inc.

[2] Lovelock, Christopher H. 2004. Service Marketing and Management. 2nd edition. New
Jersey. Prentice Hall by Pearson Education Inc.

[3] Booms, Bernard H. dan Mary J. Bitner. 2001. "Marketing Strategies and Organization. Structures for Services Firms”. American Marketing Journal. Pp. 47-51

[4] Parasuraman, Valarie A.Zeithaml and Leonard L.Berry. 1985. "A Conceptual Model of Service Quality and its Implication for Future Research Jouurnal of Marketing, hal. 44

[5] Kotler, Philip dan Gary Armstrong. 2011. Principles of Marketing. $14^{\text {th }}$ edition. New Jersey. Prentice Hall by Pearson Education Inc

[6] Hasan, Ali. 2013. Marketing dan Kasus-Kasus Pilihan, Yogyakarta: Center for Academic Publishing Service

[7] David, Fred. R. 2006. Manajemen Strategi. Jakarta. Salemba Empat

[8] Saaty,T.L. 2008. Decision Making with The Analytic Hierarchy Process. International Journal Services Sciences. Vo.I, No.1.pp.83-97

[9] Supranto, J. 2006. Pengukuran Tingkat Kepuasan Pelanggan Untuk Menaikkan Pangsa Pasar. Jakarta. Rineka Cipta

[10] Kotler, Philip. 2000. Marketing Management. New Jersey. Prentice Hall by Pearson Education Inc.

[11] Zeithaml, Valarie A, Parasuraman. A, and Leonard L. Berry. 2000. Delivering Quality Service: Balancing Customer Perceptions and Expectations. New York. Macmillan.Inc

[12] Ansoff, H. Igor. 2007. Strategic Management. New York. Palgrave Macmillan

[13] Rangkuti, Freddy. 2013. Analisis SWOT, Teknik Membedah Kasus Bisnis, Jakarta. PT.Gramedia Pustaka Utama

[14] Rangkuti, Freddy, 2011. SWOT Balance Scorecard: Teknik Menyusun Strategi Korporat yang Efektif Plus Cara Mengelola Kinerja dan Risiko. Jakarta. Pustaka Gramedia Utama 